\title{
SAGES presidential address: a SAGES Magical Mystery Tour
}

\author{
L. Michael Brunt ${ }^{1}$
}

Received: 11 August 2015/Accepted: 17 August 2015/Published online: 28 September 2015

(C) Society of American Gastrointestinal and Endoscopic Surgeons (SAGES) 2015

The last time SAGES met in Nashville was in 1994-in this same venue in fact. The SAGES President was George Berci and so it is a special privilege to be standing here where Dr Berci gave his address 21 years ago almost to the day. Moreover, when I consider the icons of minimally invasive surgery and fathers of the laparoscopic revolution who have been in this position, I am indeed humbled and incredibly honored to have had the opportunity to serve as your SAGES President this past year.

I was a relative newcomer to SAGES in 1994, having joined the society 2 years prior in 1992 at the urging of Nat Soper; 1992 was also my first SAGES meeting in Washington, DC, and it was a meeting I will never forget-the energy and excitement were literally palpable because the laparoscopic revolution was underway in full force and it seemed almost every week brought some new technology or technique to clinical practice. SAGES was, of course, leading that revolution and as I reflect back, it is amazing to see the evolution of our society to one that has impacted education and training, research, and innovation in virtually every aspect of GI and endoscopic surgery. That meeting, coincidentally and perhaps propitiously for me, was also the debut of the Lap Rappers and the precursor to the Friday night main event that has become a signature feature of every SAGES meeting.

But it was only 3 years prior to that 1992 meeting that SAGES was in reality something of a backwater society, a society of visionary surgeons committed to performing

L. Michael Brunt

bruntm@wustl.edu

1 Section of Minimally Invasive Surgery, Department of Surgery, Washington University School of Medicine, $660 \mathrm{~S}$ Euclid Ave., Box 8109, St. Louis, MO 63110, USA flexible endoscopy in surgical practice. I'd like to examine a bit of the pathway that allowed SAGES to evolve as it did, highlight some of our important current initiatives, and then end with a few personal reflections. Let me begin by reviewing with you what I consider to be 3 of the sentinel events in the life of SAGES. I'd like to first acknowledge a number of individuals who helped provide material for this portion of my talk: Gerald Marks, Ken Forde, Jeff Ponsky, Rick Greene, Nat Soper, and Barbara Berci.

\section{SAGES and the laparoscopic revolution}

In 1989, the SAGES meeting was held in April in Louisville, Kentucky. About 6 weeks before the meeting, Barbara Berci received a call from Jacques Perrisat who told her he had a video of a laparoscopic cholecystectomy (lap chole) that he would like to show. There was some confusion at first- "cholecystostomy you mean," she said; "Non, cholecystectomy" he replied. The program was full, but Barbara called Wayne Schwesinger the program chair for the meeting and told him they had to find a spot for this. So Professor Perrisat was given a slot in the Exhibit Hall to show his video; an announcement was put into the meeting packets of a special video presentation during one of the breaks. This story, by the way, was retold at the 2009 meeting and you can read Professor Perrisat's description about it in Surgical Endoscopy [1]. At that SAGES meeting there were about 210 attendees and perhaps $60-70$ of these showed up to watch the lap chole video. The exhibit hall in 1989 was a shadow of itself today with only about 20 exhibitors total.

The impact and importance of Professor Perrisat's video was immediately apparent to the SAGES leaders there (Fig. 1). It was described as "visually striking, a 


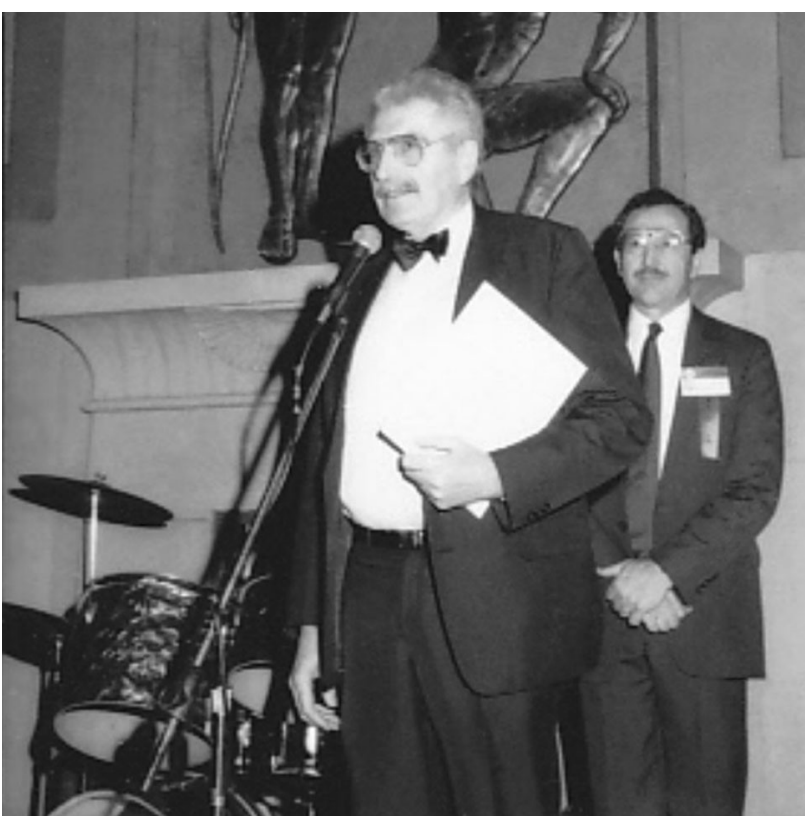

Fig. 1 Jacques Perrisat at 1989 SAGES meeting

tremendous awakening, amazing..." But what came next was crucial. Several of the SAGES leaders convened afterwards and said we can't leave this meeting without discussing what this means. They recognized that something significant had happened, that it was a disruptive technology, and they knew they had to act on it. It was never a question of whether-but of how.

So why did SAGES leaders decide to move on this? (1) One was concern that gastroenterologists might consider doing this since some were already doing diagnostic laparoscopy and SAGES had already been engaged with them over the flexible endoscopy issues and realized what could be at risk; (2) these surgeons were accustomed to doing procedures using an endoscope, so the translation to the laparoscope with the effects of magnification and improved visualization made sense; and (3) what other surgical society was going to step up and take on this issue?

SAGES quickly put together a position statement crafted by Ken Forde and others and published in Surgical Endoscopy and in the Bulletin of the American College of Surgeons stating that only someone who did open cholecystectomy should do it laparoscopically [2,3]. Things moved rapidly from there. Within less than 1 year of this video being shown at the meeting the first guideline on lap chole came out from SAGES. George Berci and Alfred Cuschieri collaborated on a book entitled Laparoscopic Biliary Surgery which was published in 1990 and sold over 25,000 copies in multiple languages [4].

The 1st lap chole postgraduate course was held at the 1990 meeting in Atlanta and over the next year the SAGES office was bombarded with up to 100 calls per week from surgeons asking about courses for cholecystectomy. There were 1-day courses popping up all over that were highly variable, and so SAGES developed a series of "train the trainers" courses so that surgeons at academic and training institutions would be able to teach laparoscopy to their trainees and other surgeons. In doing this, SAGES helped provide some formal structure to the courses that were being taught. Not only did SAGES help in the training for lap chole, but to quote Jeff Ponsky, "SAGES learned how to lead an entire nation and world in the laparoscopic revolution and it was with lap chole that the whole concept of proctoring was born."

At the 1990 meeting in Atlanta, attendance had more than doubled to 450 and at Monterrey in 1991 was 775, with many more who called SAGES and begged to get into the meeting and the laparoscopic hands-on courses. And the growth of the annual meeting continued at an almost exponential rate through the 1990s until the 2000 mark was reached first in 2002 and then again in 2007-a level at which we have stayed ever since (Fig. 2).

Between 1990 and 1992, about 15,000 general surgeons in the USA were trained in this procedure. SAGES needed faculty for the 22 train the trainer courses in the first year and there were more young surgeons who had been in some of these other courses, and so unlike the traditional surgical paradigm where you teach courses when you are mid-career or later, these train the trainer courses were largely taught by the young surgeons such as Nat Soper, John Hunter, Lee Swanstrom, Jonathan Sackier, Joe Petelin and many others. Why did they get involved? According to Nat Soper, "SAGES was this radical breakaway society and this was another breakthrough technology. You couldn't get an abstract on lap chole on at a mainstream meeting and SAGES was willing to let young people come in and do things and get involved in teaching." He said, "It's hard to appreciate today how much against the grain this went."

These young surgeons were trained in flexible endoscopy and were doing biliary surgery already and so they

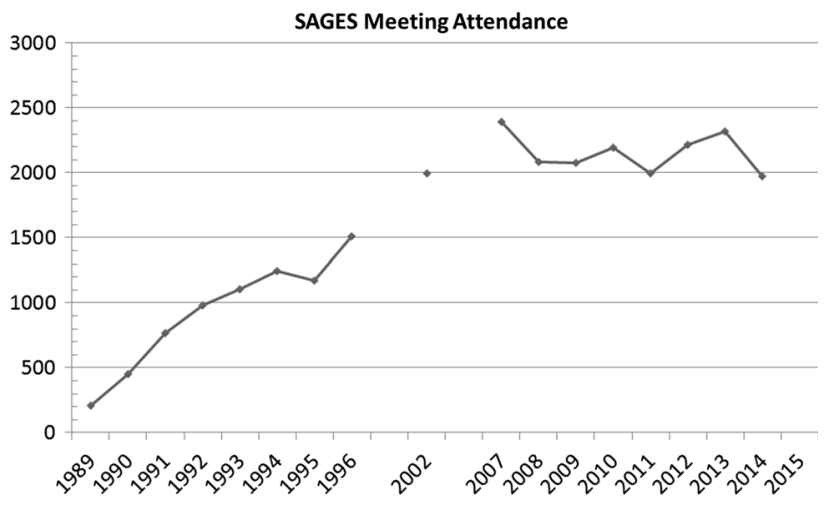

Fig. 2 SAGES meeting attendance 1989-2015 
readily embraced laparoscopy and put together clinical outcomes studies to address some of the key questions early on. The association that some had with major academic institutions helped establish credibility to the movement. They also established a new pathway to building an academic career, and out of this, a new generation of SAGES leaders emerged, several of whom went on to become President of this organization. Despite the obvious advantages and excitement that accompanied the laparoscopic revolution, there was a problem and that was the increase in the rate of biliary injuries.

In New York State, the presence of biliary and other serious injuries almost led the state to put a moratorium on this procedure-fortunately that did not happen thanks to the efforts of Ken Forde, and Rick Greene who was SAGES President [5]. Unfortunately, despite a quarter century of surgeons performing lap chole, the problem of biliary injury has not gone away-a problem to which I will return.

\section{The SAGES Education and Research Foundation}

A 2nd sentinel event in the life of SAGES was the formation of the SAGES Education and Research Foundation in 1999. The birth of the SAGES Foundation was due to the vision of SAGES leaders Greg Stiegmann, Ken Forde, Jeff Ponsky, and Barbara Berci and others who saw the need for an organization separate from SAGES in which the strategy was long term.

They recognized even then that the days of abundant support from industry would not last forever and they saw the need well before the heightened awareness regarding conflict of interest issues that a corpus of dollars that could be used to independently fund projects would be in the best interests of GI and endoscopic surgery, patient care and surgical education over the long term. They held a strategic planning meeting in New York City and went about raising the funds to set this in motion. The corpus was started with incredibly generous donations from industry. The founders also put their money where their mouth was with each Foundation Board member committing to donating $\$ 5000$ over time.

The Foundation has been ably led by former SAGES Presidents Greg Stiegmann, Rick Greene, Bruce Schirmer and now Desmond Birkett who takes over as President of the Foundation as of this meeting (Fig. 3). The Foundation is a big part of the success of our organization and has provided critical support to numerous projects and programs over the years-FLS, FES, FUSE, the Global program, the Career Development Award, the Brandeis award, numerous research grants and other projects. SAGES has regularly contributed funds to the Foundation and also matches member contributions annually with over $\$ 1.6 \mathrm{M}$ total given to the Foundation. But we have received more in return, for every $\$ 1$ SAGES has given to the Foundation, SAGES has received back over $\$ 1.5$ to fund SAGES education and research projects-over $\$ 2.5 \mathrm{M}$ in total.

Many SAGES members have given generously to the Foundation, most notably Dr Pon whose recent philanthropic gift will support life-changing advances in laparoscopic surgery in the developing world. But we can and must do more. The Foundation needs greater support by our active membership-I regret to say, of the over 3700 active members of our organization, the annual contribution rate is under $10 \%$-we can do a lot better.

Let me tell you a brief story from one of our SAGES members-Rob Lim. Rob has been a leader of our military working group for the last several years. Earlier this week, he received the Gold Foundation SAGES Clinical Excellence and Humanism in Medicine award. Rob was unable to accept the award in person as he was recently deployed to Afghanistan for 6 months. Instead, he has requested that the $\$ 1000$ honorarium for his award be donated to the SAGES Foundation - he said very simply "the donation is the least I could do for SAGES after all it has done for my career and professional development."

So let me charge each of you to make the Foundation a top priority for your charitable giving every year. No gift is too small, the important thing is to become a donor-at any level. Join the SAGES World Campaign the Foundation has initiated this year to extend SAGES global contributions to education, research and training. The Foundation is a part of the SAGES brand and it's up to us to support it and help expand the reach of our organization.

\section{BSC Management Corporation}

A 3rd sentinel event for SAGES was a decision made very early in the life of our society and that was the decision in 1984 to hire Barbara Saltzman, who of course later became Barbara Berci, to manage SAGES. SAGES had been managed by a PR firm but needed someone who could do more administrative and secretarial work. Gerry Marks had known Barbara who lived in Philadelphia at the time and it was he who proposed the idea to her; Tom Dent and Ken Forde interviewed her and made the decision. They described her as smart and a quick learner, highly energetic, articulate and persuasive. She took care of things in a business-like fashion, and was organized, and perceptive.

She understood this was an opportunity to facilitate something new, to work with a group of young, idealistic surgeons who were not in the traditional mold and also was an opportunity for her to develop an organization and grow as well. She learned about what SAGES was engaged in from a 
Fig. 3 SAGES education and research foundation presidents. From left to right, Greg Stiegmann, Desmond Birkett, Rick Greene, Bruce Schirmer

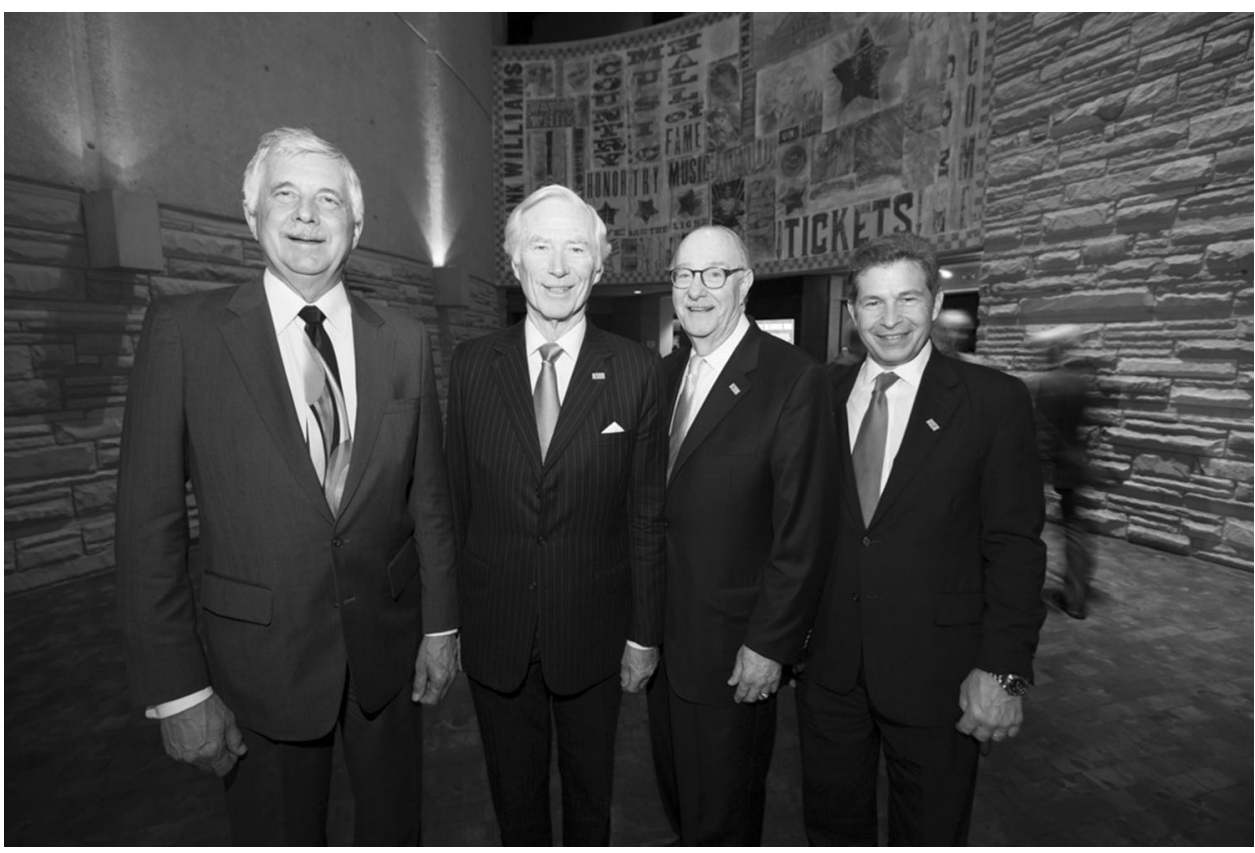

surgical standpoint and was willing to ask questions. She understood the people and the potential for the growth of the society. She was persistent, always working to do the right thing, and hard to say no to, especially when she said "you have to do this now." She had great strength and was devoted in a way that few were devoted. Surgeons looked up to her as a voice of conscience within the organization-it was a different and unique relationship. To quote one SAGES leader, "SAGES is what it is today in part because of her exemplary vision, and remarkable dedication."

SAGES soon became family for her-not just as SAGES Momma which of course she is and always will be-but as she and George Berci married in 1989 and she and BSC moved to LA. Initially, Barbara managed SAGES by herself but as the organization grew, she hired some part-time staff, and then gradually some full-time employees, and in 1993 a young woman walked into Barbara's office looking for temporary employment as a secretary while she pursued a musical career as singer. Her only stipulation was that if she were called for an audition she could get off work to do that. Fortunately for SAGES, the musical career did not work out, and Sallie Matthews quickly took on more and more responsibilities within SAGES. Like Barbara, she's very bright and clearly had a lot of talent when it came to managing an organization and group of surgeons. In 1998, Sallie became Executive Director of SAGES and in 2008 President and CEO of BSC, and Barbara has of course continued to be involved in SAGES and the Foundation.

BSC now has over 50 employees and manages 18 societies, but the personal attention that we get makes it seem we are the only one. As anyone who has been in this position would tell you, I can't imagine leading this society without Sallie at the helm. Together, Barbara and Sallie have given our organization continuity of management for more than 30 years and collectively have a phenomenal institutional memory about SAGES and all its operations and activities (Fig. 4). But perhaps most importantly, and what sets aside this relationship from any other society I have been a part of, is how spiritually and intellectually invested they are with us and our mission - they are a part of the very fabric of our organization and we owe them a huge debt of gratitude, and Barbara, Sallie and the entire BSC staff should be recognized for all their work and contributions on behalf of our organization.

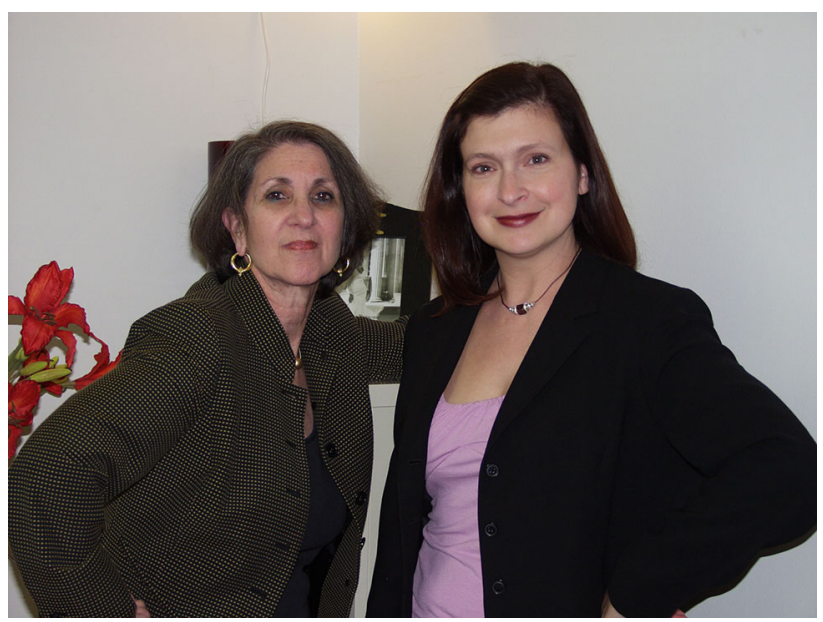

Fig. 4 Barbara Berci and Sallie Matthews, BSC Management, Inc 


\section{The present}

Let me now turn to the present and spend a few moments highlighting some of SAGES recent efforts. This year we reached a milestone as we celebrated 10 years of the FLS program, a story that was featured in the Bulletin of American College of Surgeons last fall [6] —another incredible SAGES undertaking and story in and of itself. And SAGES awarded the 10,000th FLS certificate-to Chris Crawford a general surgery resident at the Marshfield Clinic in Wisconsin. FES also went live last year and will be required of all graduating general surgery residents in the USA as of 2018.

It's been 15 years since To Err is Human brought to attention the problem of potentially preventable hospitalrelated injuries and deaths [7]. SAGES has undoubtedly impacted this area in terms our many education and training programs but we can do more. Indeed, a goal of this Presidential year for me has been to enhance awareness and efforts of our society around patient safety. Aurora Pryor and Michael Holzman have put on a fabulous meeting with the theme of "Promoting a Universal Culture of Innovation, Safety, and Improved Outcomes in GI Surgery." I hope you have noticed throughout the program the band-aids labeling various sessions and talks that relate to patient safety issues.

We also have a phenomenal opportunity right before us with the FUSE program [8]. The brainchild of Steve Schwaitzberg, in just 3 years FUSE has gone from concept to reality under the leadership of Dan Jones, Liane Feldman, Pascal Fuchshuber and Tom Robinson. FUSE went live this past September and has already created tremendous interest across the surgical world. I dare say there is no other area in surgery which so ubiquitously impacts almost everything we do and yet about which surgeons are so lacking in fundamental knowledge and understanding. I certainly did not realize how uninformed I was about surgical energy until I got involved in the FUSE project. Let's take just one example-OR fires.

It's estimated that there are 200-240 OR fires that occur in the USA every year [9], not a large number certainly when you consider the millions of procedures performed annually. And most of these are minor and do not cause any harm, but up to $20-30$ are serious and result in disfiguring injuries or even death. We have every element needed to start a fire in the OR; fuel with our drapes and alcohol-based preps, igniters with our electrosurgical equipment and high intensity light cords, and oxidizersoxygen. And it can happen in a flash-literally.

A story that I have heard on more than one occasion is a surgeon was taking off a mole or cyst on the scalp or face, oxygen was being given via nasal cannula, the incision was made, the electrosurgical unit was activated and there was a spark and flash beneath the drapes-and this can be the result-extensive 2nd degree facial burns. This young woman's story was told on the Today show 4 years ago [10], and unfortunately it is not the last one like it I have heard about since then. This is a totally preventable event and is a top safety priority for the FDA which has an OR Fire Prevention week each fall and with whom SAGES is engaged on this issue. It simply requires that we all understand the risks and are vigilant about taking the appropriate precautions.

FUSE can make a difference here I am convinced. This is our program and SAGES members need to lead the way, so let me pose a challenge to you all: that every surgeon in this audience over the next 12 months become FUSE certified - and not only that, but once you are FUSE certified, become an energy safety leader and advocate at your home institution. Give talks about it, engage your OR leadership, discuss ways to prevent OR fires and other electrosurgical injuries. This will I'm convinced have a major impact on how our operative teams approach energy safety in the OR and a positive patient impact.

\section{Safe cholecystectomy}

The 2nd SAGES patient safety initiative goes back to the problem of laparoscopic cholecystectomy and biliary injury. Although it's been 25 years since lap chole was introduced into practice, bile duct injuries continue to occur. Even if the biliary injury rate is only $0.2 \%$-and it may be higher, especially for acutely inflamed gallbladders-that translates to 3000 or more biliary injuries in the USA each year. A bile duct injury can be a devastating outcome for the patient who otherwise would have undergone an outpatient procedure with minimal pain and prompt return to normal activities, and it can also be emotionally devastating for the surgeon.

This past year, at my direction, SAGES has formed the Safe Cholecystectomy Task Force, led by Rob Fanelli and Horacio Asbun with the mission to enhance a universal culture of safety for cholecystectomy in an effort to reduce biliary injuries (Fig. 5). A multimodal educational program is being developed to address this issue but there are already things we can do now to move this initiative forward by incorporating these 6 steps into our practiceswhich are the cornerstone of the Safe Chole program [11].

1. Learn about the critical view of safety and use it on every cholecystectomy case (Fig. 6)

2. Consider an intraoperative time out-a brief stop pause-during the procedure before clipping or cutting any ductal structures

3. Understand aberrant anatomy. 


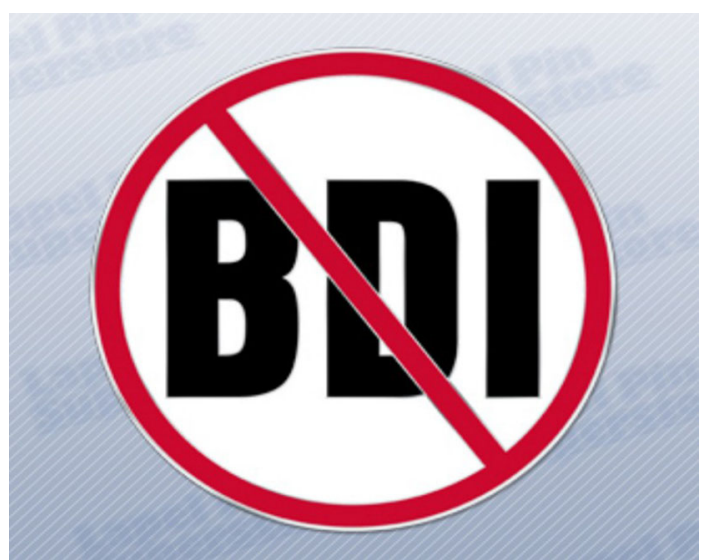

Fig. 5 SAGES “Prevent Bile Duct Injury” logo
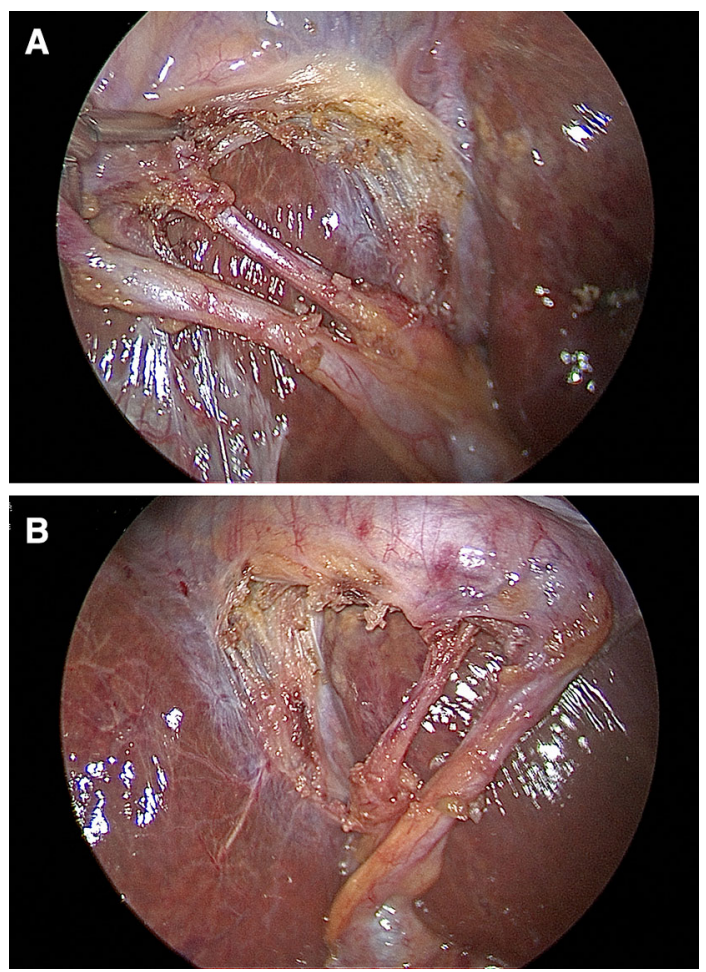

Fig. 6 Operative photograph of critical view of safety during laparoscopic cholecystectomy. A anterior view, B posterior view

4. Use cholangiography or other methods to image the biliary tree intraoperatively liberally.

5. Recognize when the dissection is approaching a zone of danger and stop before entering that zone. If conditions around the gallbladder are too unfavorable, put in a cholecystostomy tube or do a subtotal cholecystectomy.

6. Finally, for really difficult cases, consider getting help from another surgeon.

Go to the SAGES web site and read more about this. Impacting this problem will not be easy because it will require a change in culture about an operation that surgeons know how to do and do well and that the vast majority of time is straightforward and uncomplicated. But if we don't take this on, then this problem will never go away, and we will be abdicating our responsibility to our patients to make surgery safer. So I implore you to adopt these measures, spread the word about the SAGES Safe Chole program, and together let's start addressing this problem now!

\section{Reflections}

For the final portion of this address, I'd like to shift gears a bit and share with you a few thoughts and concepts I have gleaned from my perspective of 25 years in surgical practice.

1. There are multiple pathways to success.

My own pathway to the present has been a bit of a nonlinear one. I started out as a general and endocrine surgeon, and although I began doing laparoscopic surgery in 1990, I did not really make that the main focus of my practice until a few years later. I served on some SAGES committees in the 1990s but I think I first became really noticed when at the Sing-off in 2001 at the meeting in St. Louis, I debuted the "Scoping Stones" and was subsequently drafted into the Lap Rappers.

Seriously though, when I Co-Chaired the SAGES Continuing Education committee, Dan Smith gave me the opportunity to produce the SAGES Grand Rounds video series, and although these never quite became the best sellers that I had hoped for, there were two things of significance that did come out of that project: (1) it gave us some additional quality materials that helped SAGES connect with and become a member of the SCORE council, and (2) it gave me the experience in filming and video production that was invaluable in producing the Berci documentary film. So my message to you is take advantage of the opportunities that come your way in SAGES. A SAGES leader will support you and get you on a committee or involved in a resident course and help push your name along, but much more important is what you make of that opportunity, because SAGES ultimately is a society that functions as a meritocracy and that rewards individuals who volunteer for projects, who are responsive and organized, and get the work done to move our society's agenda forward.

2. Put yourself back on the learning curve

Some of you are still very much on your learning curve whether in residency, fellowship or even the first few years of your practice-but the learning curve never 
stops in surgery. In his book Outliers [12], Malcolm Gladwell talks about the factors that differentiate individuals who have achieved not just success, but extraordinary success in their life's work. Although there are many variables, one factor is the $10,000 \mathrm{~h}$ rule (Ericsson's work that shows that what differentiates levels of performance; his early studies interestingly looked at musical performance) is that the people at the top not only work harder, but much, mисh harder than anyone else, and that takes me to The Beatles since this is after all a SAGES Magical Mystery Tour. Before the Beatles came to America to appear on the Ed Sullivan show in 1964, they had been playing together for 7 years. They were still a struggling young rock band when they were invited to Hamburg, Germany, in 1960 to perform in the clubs there. It was an unusual arrangement-they played nonstop shows, hour after hour, up to $8 \mathrm{~h}$ a day. In Gladwell's book, he writes that "John Lennon said, 'in Liverpool we only played for an hour and just our best numbers, so we had to find a new way of playing'" [12, p. 49]. Over the next year and a half, they did 3 stints in Hamburg, performing over 270 nights and an estimated 1200 times live. According to Gladwell, Philip Norman, who wrote the Beatles biography "Shout," said "they were no good on stage when they went there, but they were very good when they came back, and they sounded like no one else. It was the making of them." Amazingly, their greatest artistic successesSgt. Peppers, Magical Mystery Tour and the White Album came only 5 years after that return from Hamburg.

I think the early days of the laparoscopic revolution were somewhat like that - a generation of young surgeons who had for the most part not done any laparoscopic surgery in training. In fact, a survey of SAGES Past Presidents from 1995 to the present showed that of the individuals who finished training 1989 or earlier, only $1 / 4$ had ANY experience with laparoscopy before they started doing lap chole's. And I am quite certain that I will be the last SAGES President who did not do a single laparoscopic case during residency training.

So what did they do? Well, they went to the lab and did procedures there, they worked with GYN surgeons at their institutions who were doing laparoscopy, they practiced and honed their skills, learned how to suture, worked with industry to develop the tools needed to perform more advanced and complex cases, and carefully introduced new techniques into surgical practice. Out of this also was born the impetus for the development of formal skills training for surgical residency, something that did not even exist prior to that time. They also were not willing to limit themselves by the present constraints and considerations of what was possible.

3. Don't be so quick to claim your limitations when you have never really tested them [13]

I first saw this quote a few years ago on the message board in the locker room of one of our pro sports team in St Louis. Although our hockey team has never quite fulfilled this admonition with playoff success, I've thought about it a lot and it's too easy to get comfortable with your situation oftentimes and not challenge yourself, but you won't ever realize your full potential if you don't push yourself from time to time. My original plan this year was to cut back a bit clinically in order to devote more time to SAGES, but those plans quickly dissolved due to some faculty departures and this has instead turned out to be the busiest clinical year I've ever had by far-something I could not have managed without a lot of support from my colleagues and staff. But the point is sometimes you have to reach down inside yourself for that extra gear in order to meet a challenge or to carry you through difficult times.

In the movie "A League of Their Own" about a women's professional baseball team during World War II, one of the star players complains to the manager (played by Tom Hanks) that she wants to quit because it has just becomes too hard-his reply is, "of course it's hard, the hard is what makes it so good."

4. Keep the main thing the main thing

A senior surgeon said to me early in my career, take care of your family first, and everything else in your career will fall into place. I've been blessed by family in many ways. There's my Wash $U$ family, in particular, my wonderful partners and colleagues past and present: Brent Matthews who I learned so much from during his 10 years in St Louis, Chris Eagon and Michael Awad; my staff Kim and Mary who have been such a huge support this year in so many ways and have had to take on more and more responsibilities without once complaining, Peggy Frisella who keeps our MIS Institute going, and my OR staff-Julie and Sly and the rest of the OR team.

There's my SAGES family; yes, SAGES is really like family. I owe so much in my SAGES career to so many individuals but in particular, a special thanks to Nat Soper who was my colleague at Wash U for many years and who got me involved in SAGES and for his continued support, and to Mark Talamini, Steve Schwaitzberg, and Dan Deziel, for their friendship and mentorship over the years; the SAGES Executive Committee (Fig. 7) who work so hard and commit their best to leading the society to achieve its goals and 
Fig. 7 SAGES Executive Committee 2014-15. From left to right, Sallie Matthews, Brian Dunkin, L. Michael Brunt,

Tonia Young-Fadok, Dan Jones, Adrian Park, Gerald Fried, Danny Scott (inset)

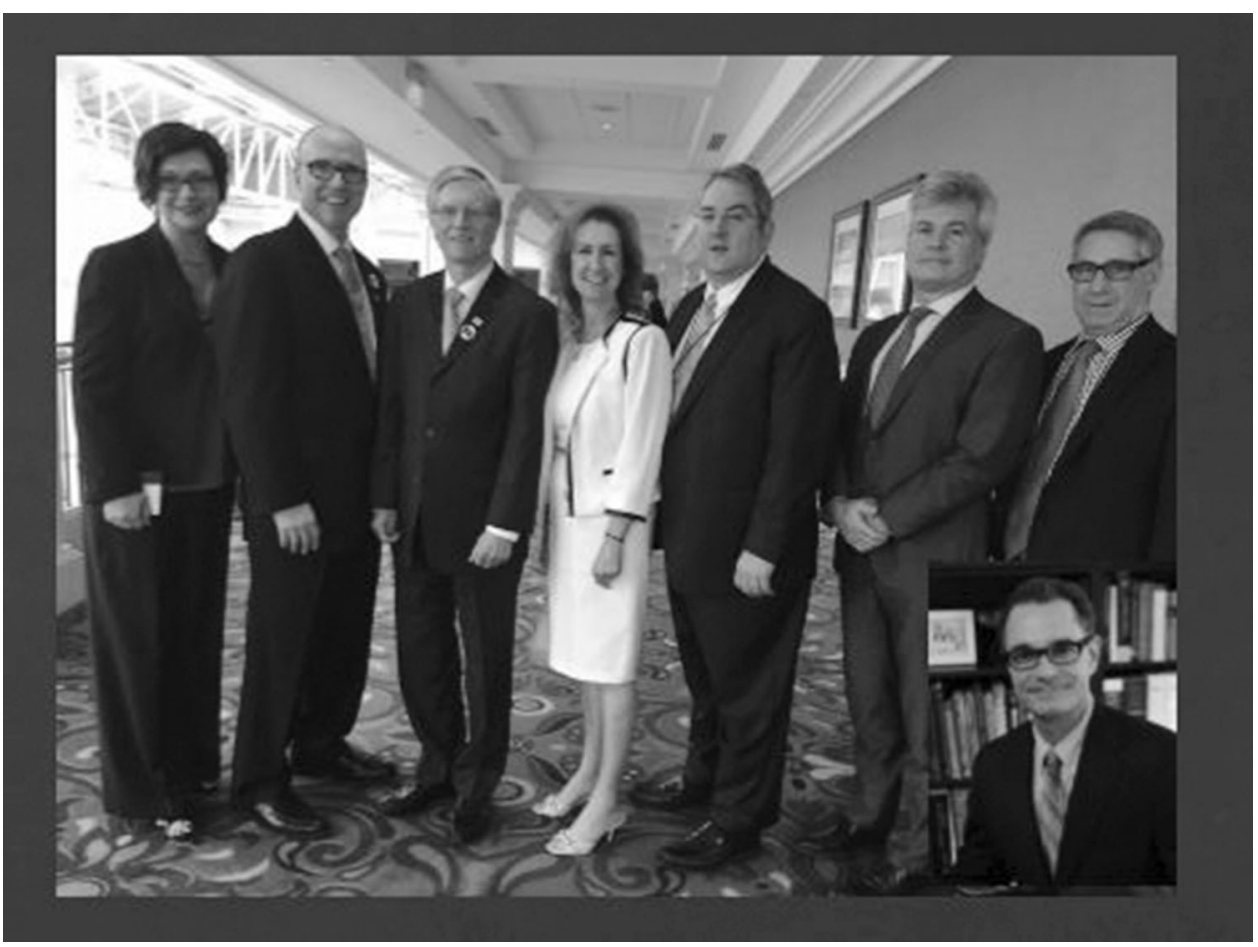

aspirations; Sallie Matthews who has been so incredible to work so closely with this year. Her calming influence and incredible knowledge about SAGES and our organization have been amazing to behold.

And then there's my family, family-my Mom and Dad who gave this small town Mississippi boy the opportunity to pursue a dream and encouraged me every step of the way and who sacrificed so I could get a good education and, our two wonderful boys-Eric and his wife Lindsey and our precious granddaughter, Timothy and his fiancee Stephanie; I'm so proud of them and the fine young men they have become. And my dear wife, Beth, who is so accomplished in her own right and is not only one of the best liver and GI pathologists in the world, but also a wonderful mother and a loving wife with a kind and caring heart. Her indomitable spirit is an inspiration to me on a daily basis. I can't thank her enough for all her love and support this year.

One of my favorite movies is Field of Dreams. I won't recant the story in detail but it's about a farmer in Iowa by the name of Ray Kinsella who hears a voice telling him to build a baseball field on his farm to which Shoeless Joe Jackson and other 1919 era ballplayers return from the afterlife to play games. Perhaps it resonates with me because as a kid I dreamed of playing baseball, but instead became a doctor like Archie Moonlight Graham in the movie, but also because at the end, Ray's Dad who had also been a baseball player and had passed way years before, returns to play on this field and they have a game of catch and as his Dad surveys the pristine field and Ray's family he asks-is this heaven? And Ray says no it's Iowa, but then he thinks again as he looks around at what he has and says "maybe it is heaven." When I consider the many blessings in my life, my friends and colleagues, and family, for me, this is a bit of heaven on earth. It has been a great honor to serve as your SAGES President. Thank you so much and God Bless.

Acknowledgments The author wishes to acknowledge the following individuals who were interviewed for the historical section of this talk: Gerald Marks, Ken Forde, Jeff Ponsky, Rick Greene, Nat Soper and Barbara Berci.

\section{Compliance with ethical standards}

Disclosures L Michael Brunt has no conflicts of interest or financial ties to disclose.

\section{References}

1. Brunt LM, Greene FL, Forde KA, Perissat J (2013) SAGES video classics. Surg Endosc 27:4581-4588

2. Statement on laparoscopic cholecystectomy. Issued by SAGES Oct 18,1989

3. Statement on laparoscopic cholecystectomy (1990) ACS Bull $75: 23$ 
4. Cuschieri A, Berci G (1990) Laparoscopic biliary surgery. Blackwell Scientific Publications, London

5. Greene FL (1992) New York state health department ruling: a "wake-up" call for all. Surg Endosc 6:271

6. Brunt LM (2014) FLS: celebrating a decade of innovation in surgical education. ACS Bull 99:10-15

7. "To Err Is Human: Building a Safer Health System." Institute of Medicine, National Academy of Sciences, the National academies Press, 2000

8. SAGES FUSE Program. www.fuseprogram.org
9. Clarke JR, Bruley ME (2012) Surgical fires: trends associated with prevention efforts. Pa Patient Saf Advisory 9:130-135

10. www.today.com/id/45117440/ns/today-today_health/t/operatingroom-fires-hurt-hundreds-each-year/\#.VbUiYPIViko

11. www.sages.org/safe-cholecystectomy-program/

12. Gladwell M (2008) Outliers: the story of success. Little, Brown, and Co., New York, pp 47-50

13. Ngo K (2013) Let's Do This. CreateSpace Independent Publishing 